\title{
The relationship between Internet of things and search engine optimization in Jordanian Telecom- munication Companies: The mediating role of user behavior
}

\author{
Nawras M. Nusairat ${ }^{\mathrm{a}}$, Jassim Ahmad Al-Gasawneh ${ }^{\mathrm{a}}$, Abdalrazzaq Aloqool ${ }^{\mathrm{a}}{ }^{*}$, Khalid N. Alzubi ${ }^{\mathrm{b}}$, Abdel \\ Hakim O. Akhorshaideh ${ }^{c}$, Jamal M. Joudeh ${ }^{a}$ and Haya Samih Ibrahima
}

\author{
${ }^{a}$ Applied Science Private University, Jordan \\ ${ }^{b}$ Department of Management information Systems, Al-Balqa Applied University, Jordan \\ ${ }^{c}$ Department of public Administration, University of Jordan, Jordan

\section{H R O N I C L E \\ A B S T R A C T}

Article history:

Received: March 18, 2021

Received in revised format: April

18,2021

Accepted: June 30, 2021

Available online: June 30, 2021

Keywords:

Internet of Things

Search Engine Optimization

User Behavior

\begin{abstract}
This research paper aims to investigate the effect of Internet of Things (IoT) on Search Engine Optimization (SEO) by considering the mediating role of user behavior on this effect. A conceptual research model was developed in accordance with the UTAUT and based on a thorough analysis of extant research. A self-handled questionnaire survey was administered to a purposely selected sample of employees working in telecommunications companies in Jordan. A dataset of 131 usable questionnaires were subjected to data analysis using SmartPLS 3.0. The main findings showed that IoT affected SEO and user behavior. User behavior was also found to be significantly predicted by IoT and to mediate its effect on SEO. The results revealed the significance of SEO as an emerging effective electronic marketing tool in encouraging consumers' adoption of new technologies. The paper ends with a discussion of findings, conclusions, and areas for future research.
\end{abstract}

C 2021 by the author: license Growing Science, Canter

\section{Background}

People use the internet for almost everything in their daily life, basically communications. Continuous developments in internet technology enables it to influence people's daily activities (Zeinab \& Elmustafa, 2017; Khanna \& Kaur, 2019). Internet technology connects people and physical objects with each other and with external entities via internet infrastructure, this is known as the Internet of Things (IoT) (Atzori \& Morabito 2010; Rio \& Banker, 2014; Nguyen \& Simkin,2017; Yerpude \& Singhal, 2017). IoT aims to create a new value through the exchange of information and knowledge between people and objects (Zeinab \& Elmustafa, 2017; Kumar \& Mallick, 2018). This relationship can be realized using various technological solutions provided by internet providers. The Internet becomes a main source for disorganized information (Lemos \& Joshi 2017) because of the existence of billions of websites. Therefore, it becomes a necessity to make the search for specific results easy and efficient (Ziakis et al., 2019). The urge for information spurs the emergence of online "Search Engines" which become the most used tool for information seekers (Goldman, 2005). The search engine acts as an intermediary between consumers and websites, through which consumers can select between organic and sponsored links (Berman \& Katona, 2013; Kritzinger \& Weideman, 2013). As a result, a mechanism to facilitate searches for specific websites or results was founded; search engine optimization (SEO). SEO is also used to promote specific websites on the top of SERPs (Search Engine Results Pages) (Bhandari \& Bansal, 2018; Rashid et al., 2018; Ahmad et al., 2020), to improve the rank for search results, and to get more page views requested by the users (Ištvanić et al., 2017; Grubor \& Jakša, 2018). Recently, marketers have started utilizing this tool for promoting their products on the internet (Bhandari \& Bansal, 2018; Hammouri, Q., \& Altaher, 2020), then, it * Corresponding author.

E-mail address: ㅅaloqool@asu.edu.jo (A. Aloqool)

(C) 2021 by the authors; licensee Growing Science, Canada. doi: $10.5267 /$ j.ijdns.2021.6.016 
has been considered one of the most important techniques in internet marketing. IoT and SEO are used by employees in most workplaces, especially firms in the information technology and telecommunication industry. Such firms provide services for the technology that supports IoT, at the same time they use SEO in their marketing strategies. Employees who work in telecommunications firms are users of such technologies. User-behavior refers to the way users interact with a particular product (Johansson, 2016). Understanding user-behavior for technologies like IoT and SEO becomes important in several contexts including user experience design, software development and marketing. To this end, users must be observed, and this observation should be analyzed (Johansson, 2016; Ngah et al., 2021). Today, and after twenty years of releasing the IoT as new terminology by Kevin Ashton (Kramp et al., 2013; Witkowski, 2017; Chin et al., 2019), the applications of IoT are still doubtful in terms of accepting and using this technology especially in developing countries. Like other emerging technologies, studies investigating IoT are mainly inspired by technology acceptance models such as Unified Theory of Acceptance and Use of Technology (UTAUT) (El-Masri et al., 2017; Ziakis et al., 2019; Al-Saedi et al., 2020; Arfi et al., 2021). In the meantime, huge data is being uploaded automatically by ample sources from smart devices exploiting IoT, while users are thirsty to reach their information simply and efficiently. Therefore, SEO becomes important for users to find what they want quickly and for companies as an online marketing tool. Accordingly, this study tries to figure out if adopting and accepting IoT technology -which results in transferred bulk information- influences results generated from search engines, conjointly it tries to explore the effect of users' behavior on the relationship between IoT and SEO.

This current study introduces SEO as an important e-marketing channel to companies. Accordingly, two factors of (UTAUT) model, namely: (performance expectancy, social impact) along with "cost" and "security" are used to represent "IoT construct" as an independent variable, expressing users' acceptance of IoT, which is linked to SEO as a dependent variable with considering the mediating role of user behavior on this linkage from the perspective of telecommunication companies' employees.

\section{Literature Review}

\subsection{Internet of Things}

Talking about any new technology should not omit the thoughts of acceptance of the new technology and users' behavior. Researchers apply different models like the Theory of Reasoned Actions (TRA), Theory of Planned Behavior (TPB), Technology Acceptance Model (TAM), Extended Technology Acceptance Model (TAM2), Systems and Computer Technology (SCT), Memory Module (MM), Model of Personal Computer Utilization (MPCU), and Diffusion of Innovation (DOI) in developing and testing their hypotheses to examine users' behavior toward technology (Venkatesh et al., 2016 ; Zaky, et al. 2020; Hawamleh et al., 2020; Jaradat et al., 2020; Hammouri et al., 2021b). Venkatesh et al. (2003) introduced the Unified Theory of Technology Acceptance and Usage (UTAUT), which has inspired a substantial research addressing technology usage and user behavior (Venkatesh et al., 2012; Venkatesh et al., 2016; Williams et al., 2015; Dwivedi et al., 2019; Eid et al., 2020; Nusairat et al., 2020). UTAUT determines four main components (performance expectancy, effort expectancy, social impact, and facilitating conditions) that can be used to predict behavioral intention of users, with four moderator variables (age, gender, experience, and voluntariness) (Venkatesh \& Zhang, 2010; Williams et al., 2015; Khalilzadeh et al., 2017). Although the (UTAUT) model has been widely adopted in technology studies, it has been extended by considering several variables such as trust (Merhi et al., 2019), perceived risk (Slade et al., 2015; Khalilzadeh et al., 2017), and innovativeness (Slade et al., 2015; Rahi \& Ghani, 2018). In addition, security was included in different similar studies (Rahi \& Ghani, 2018; Zaky et al., 2020; Khalilzadeh et al., 2017; Merhi et al., 2019). The UTAUT was further extended to include cost (Gao \& Deng, 2012; Al-Saedi et al., 2020; Arfi et al., 2021).

\subsection{Performance Expectancy}

The term performance expectancy describes the capability of technology to provide benefits and enhance the performance of its users according to their expectations (Venkatesh et al., 2003). According to Masha'al Al Nahar (2019) it is related to user expectation of system performance, and the extent to which it allows users to achieve their goals.

\subsection{Social influence}

Venkatesh et al. (2003) defines social influence as the expected influence of others on the user to start and continue using the technology. It describes the extent to which a user perceives that others are important to use a system (Hammouri et al., 2021a; Masha'al Al Nahar, 2019). Social influence is therefore supposed to affect users in terms of changing their beliefs, attitudes, and behaviors towards technology.

\subsection{Cost}

Cost is defined as a sacrifice made in order to get something (Zainab et al., 2017). It is usually a financial assessment of all labor, products, capital, time, and utilities spent (Nwokoye \& Ilechukwu, 2018; Alghasawneh et al., 2021). It may include the cost of software and hardware, employees' training to use a system and all kinds of support provided (Folorunso et al., 2006; Hammouri \& Abu-Shanab, 2020). In the present research cost refers the amount of money paid in order to be able to use and apply IoT.

2.5 Security 
Security is the main issue that must be overcome in order to introduce the IoT into the real world. It is the main stone in building any technological work. The rapid and huge booming in anticipated IoT devices made the security more necessary (Fremantle \& Scott, 2017). Personal information for users of smart devices are now available and being exposed to websites, suggesting a definite need for this information to be secured (Herrero \& San Martín, 2017).

\subsection{User Behavior}

According to Hsiao (2018), the behavior of users when using technology has been largely addressed in extant literature. The more innovations come into life, the more research is needed to understand users' adoption and interacting with such innovations. User behavior is related to data collected from users of devices when they use services provided by the devices (Muresan, 2009). Two fundamental theories were extensively used to explain user behavior; Theory of Reasoned Action (Ajzen \& Fishbein, 1980) and the Theory of Planned Behavior (Ajzen, 1991), which are integral parts of the UTAUT model. In the current work, an extended UTAUT model was utilized to understand users' (employees) behavior towards IoT in the context of telecommunication companies in Jordan.

\subsection{Search Engine Optimization}

With the exponential growth in the number of websites, search engines needed tool programming algorithms sorting search results in user-friendly format (Ziakis et al., 2019). Website's chances to be viewed are raised by a process working on developing or adjusting in the website itself, which makes the website appears on the top of SERP, this process is termed SEO (George, 2005; Kritzinger \& Weideman, 2013; Hatab, 2014, Ahmad et al., 2020). According to Ozbal et.al (2019) SEO is "the method of optimizing a website to make it rank well in organic search results", the elements of SEO are creating keywords/phrases, indexing, content creation, link building, and social sharing.

\section{Hypotheses Development}

\subsection{Internet of Things and Search Engine Optimization}

A lot of studies examined the dimensions of IoT construction and their effects on technology, some researchers apply all of them together in addition to other factors while others apply parts of them. Moreover, Masha'al Al Nahar (2019) found a strong impact of performance expectancy and social influence on financial service quality. Social influence might come through social network sites also. Palos-Sanchez et al. (2018) consider online communities a source for increased engagement and a link to interactive content on web pages. Can \& Alatas (2017) shed light on the effect of information generated from social interaction on social platforms in increasing big data, and the effect of this big data on several technological aspects. One of the fields affected by big data is SEO. In their qualitative study about search engine marketing; Fahlström \& Jensen (2016) found that expectancy of visibility on the search engine results page (SERP) was very high and results came as expected by respondents, furthermore, respondents considered cost and time to be worth it. Ozbek et al. (2015) found that accepting technology is positively influenced by perceived cost. On the other hand, Machogu \& Okiko (2012) found that cost is a constraint from applying technology because preparing, organizing, and implementing the new system can all add up. Drivas et al. (2020) claimed that few studies were interested in the security factor and the search engines traffic. Fremantle \& Scott (2017) elaborated that all security challenges facing IoT are facing other internet technology as well. As IoT and SEO are both relying on internet and are interrelated to each other, and according to previous studies, we propose the followings hypothesis:

\section{$\mathbf{H}_{1}$. IoT has a positive and significant effect on SEO.}

\subsection{Internet of Things and User Behavior}

A reasonable number of studies correlate the dimensions of IoT construct and User Behavior or Behavior Intention as they applied and extended the UTAUAT model. According to Yu (2012); models that studied psychological theories revealed that users' behavior is expected and directed by their intention. Gao \& Deng (2012) found an indirect positive impact of performance expectancy and social influence on user behavior through behavioral intention, and a direct impact of cost on user behavior. Rahi, \& Ghani, (2018) found a tiny effect for performance expectancy on the intention to adopt internet banking while they found a substantial effect for security, Khalilzadeh et al. (2017) found a significant impact for performance expectancy, social influence, and security on behavioral intention. Merhi et al. (2019) made a comparison study between Lebanese and British users of mobile banking. They found differences in terms of the effect of performance expectancy on behavioral intention, but all respondents agreed that social influence has no effect on behavior intention while security has an impact on behavioral intention. Mei-Ying et al. (2012) found that social influence has a significant and positive influence on behavioral intention to use the electronic ticket. Cata and Martz (2015) clarified that cost plays a part in predicting mobile customer behavior. On the other hand, Zolkepli et al. (2020) figured out that cost has no effect on consumers' decision compared to quality when it comes to buying services such as mobile applications. Accordingly, we proposed the following hypothesis:

\section{H2. IoT has a significant positive effect on user behavior.}

\subsection{User Behavior and Search Engine Optimization}


User Behavior is the set of actions taken by a user interacting with the system in order to reach a goal or complete a task (Muresan, 2009). IoT relies on the interaction between users and objects (Kumar \& Mallick, 2018). Search engines, according to Mavridis \& Symeonidis (2015) attempt to monitor user experiences inside websites in order to provide feedback and to optimize ranking. Which means that user behavior supplies SEO. Drivas et al. (2020) found that user behavior had the highest impact on the increase in organic search engine traffic percent. Accordingly, we propose the following hypothesis:

\section{H3. User behavior has a positive and significant effect on SEO. \\ 3.4 The Mediating Role of User Behavior on Internet of Things - Search Engine Optimization Relationship}

IoT devices monitor, collect and store information about organizations, marketing insights, individuals, and product development (Subahi \& Theodorakopoulo, 2019). Aldossari \& Sidorova (2020) found that performance expectancy, social influence, and security play a significant role in smart home acceptance, which are - smart home -devices connected to the internet. User behavior is related to user data, collected from users of devices when they use services provided by the devices (Huang, et al. 2014). Zaky et al. (2020) found an impact for all dimensions of the UTAUT2 model -which includes performance expectancy and social influence- and for security on user behavior. Mavridis \& Symeonidis (2015) found that users' behavior on websites has an essential effect on search engine result pages (SERPs). With increasing popularity of search engines, implicit feedback (i.e., the actions users take when interacting with the search engine) can be used to improve the rankings (Agichtein et al., 2006). Drivas et al. (2020) argued that user interaction on search engines does not reflect the time and effort they spend in surfing websites. Based on the above discussion and in accordance with Baron \& Keny's (1986) and Al-Gasawneh \& AlAdamat's (2020) concept and conditions of mediation, the following hypothesis that supports the mediating role of user behavior between IoT and SEO is proposed.

\section{H4: User behavior mediates the relationship between IoT and SEO.}

\section{Methodology}

\subsection{Sampling and Data Collection Procedures:}

The present research is primarily motivated by the need to examine the relationship between IoT and SEO in Jordanian telecommunication companies. Therefore, the research population entails all digital marketing and information technology professionals working for telecommunication companies in Jordan. For a better capture of the research population, telecommunication companies in Jordan were contacted first to get the contact details of respective employees, who do fit the research purpose. Purposive sampling was then implemented to collect data from a carefully selected set of employees of interest across the telecommunication sector. An email questionnaire survey was administered to 160 professionals in total, out of which, 142 questionnaires were returned, suggesting (89) response rate. Collected data was further screened for completeness and 9 questionnaires were discarded accordingly, resulting in 131 valid and complete responses were considered for data analysis.

\subsection{Measurement and Data Analysis}

IoT in the current work was observed as a second order construct. With the majority of new technology studies, IoT was captured using four dimensions based on the extended UTAUAT model, namely; performance expectancy; social influence; cost; and security. Items used to measure these dimensions were adapted from prior research as follows; five items measuring performance expectancy adapted from (Venkatesh et al., 2003); four items to assess social influence derived from (Sheikh et al., 2017); three items and five other ones adapted from (Nasereddin and Fiqir, 2019) to measure cost and security respectively. User behavior on the other hand was measured using three items borrowed from (Ranaiey et al., 2016) Finally, SEO was captured by six items adapted from (Efendioglu \& Igna, 2011). All items across constructs were assessed on a five-point Likert scale, where (1) denotes strongly disagree and (5) denotes strongly agree. Measures were also subjected to field and academic piloting to assure clarity, relevancy, and sufficiency of the measurement scales. A dataset of 131 valid responses was carried forward to data analysis. Model validity and reliability measures were inspected first followed by descriptive statistics of the research sample demographic profile and responses to measurement items. Partial Least Squares method using the SmartPLS 3.0 was then used to test research hypotheses.

\section{Findings}

\subsection{Measurement model}

The key variables studied in this study were first-order contracts such as user behavior and SEO, as well as second-order contracts reflective-reflective structures such as the internet of things. The factors of Performance Expectancy, Social influence, Cost, and Security were used to evaluate the IoT. The IoT was chosen as a second-order factor so that a broad understanding of relevant conceptual and consensus features could be achieved. Hair et al. (2016) proposed using the second order to reduce the number of relationships and theories to be discussed in the structural model, thus simplifying the PLS path model 
and making its analysis easier. Becker et al. (2012) recommended that the method be implemented in two phases. As a result, the repeated indicator method was used to obtain first-order scores for first-order constructs in the first step. The CR. AVE of the second-order contract was determined in the second stage based on the weighing of the first-order variables. In order to determine convergent validity, factor loadings, Cronbach Alpha (CA), Composite Reliability (CR), and Average Variance Extracted (AVE) were determined, as recommended by Hair et al. (2017). As a result, it was determined that each object had a loading greater than the suggested value of 0.5 (Table $1-$ Fig. 1). Furthermore, both constructs had CA and CR values greater than 0.7, whereas AVE values were greater than 0.5, which was in line with Hair et al (2017). As a result, convergent validity was established.



Table 1

Fig. 1. Measurement Model

Measurement Model

\begin{tabular}{|c|c|c|c|c|}
\hline First order Construct & Items & Factor loading & $\mathbf{C R}$ & AVE \\
\hline \multirow{5}{*}{ Performance Expectancy } & PE 1 & 0.889 & \multirow[t]{5}{*}{0.947} & \multirow[t]{5}{*}{0.774} \\
\hline & PE 2 & 0.879 & & \\
\hline & PE 3 & 0.865 & & \\
\hline & PE 4 & 0.873 & & \\
\hline & PE 5 & 0.910 & & \\
\hline \multirow{4}{*}{ Social Influence } & SI 1 & 0.908 & \multirow[t]{4}{*}{0.961} & \multirow[t]{4}{*}{0.861} \\
\hline & SI 2 & 0.925 & & \\
\hline & SI 3 & 0.943 & & \\
\hline & SI 4 & 0.936 & & \\
\hline \multirow{3}{*}{ Cost } & $\mathrm{CO} 1$ & 0.877 & \multirow[t]{3}{*}{0.911} & \multirow[t]{3}{*}{0.774} \\
\hline & $\mathrm{CO} 2$ & 0.904 & & \\
\hline & $\mathrm{CO} 3$ & 0.858 & & \\
\hline \multirow{5}{*}{ Security } & SE 1 & 0.798 & \multirow[t]{5}{*}{0.918} & \multirow[t]{5}{*}{0.692} \\
\hline & SE 2 & 0.841 & & \\
\hline & SE 3 & 0.857 & & \\
\hline & SE 4 & 0.840 & & \\
\hline & SE 5 & 0.823 & & \\
\hline \multirow{3}{*}{ User Behavior } & UB 1 & 0.825 & \multirow[t]{3}{*}{0.909} & \multirow[t]{3}{*}{0.769} \\
\hline & UB 2 & 0.864 & & \\
\hline & UB 3 & 0.834 & & \\
\hline \multirow{6}{*}{ SEO } & SEO 1 & 0.810 & \multirow[t]{6}{*}{0.920} & \multirow[t]{6}{*}{0.659} \\
\hline & SEO 2 & 0.798 & & \\
\hline & SEO 3 & 0.855 & & \\
\hline & SEO 4 & 0.730 & & \\
\hline & SEO 5 & 0.844 & & \\
\hline & SEO 6 & 0.828 & & \\
\hline \multicolumn{5}{|l|}{ Second Order Constructs } \\
\hline Performance Expectancy & $\mathrm{PE}$ & 0.940 & 0.925 & 0.756 \\
\hline Social Influence & SI & 0.812 & & \\
\hline Cost & $\mathrm{CO}$ & 0.844 & & \\
\hline Security & SE & 0.879 & & \\
\hline
\end{tabular}

To determine discriminant validity, the Heterotrait-Monotrait (HTMT) criterion was used. Since the HTMT values were less than 0.90 , discriminant validity was verified (Henseler et al., 2015). Table 2 provides more details on this topic. 
Table 2

Discriminant validity (HTMT)

\begin{tabular}{lllllll}
\hline & CO & IOT & PE & SE & SEO & SI \\
\hline CO & & & & & & \\
PET & 0.886 & & & & & \\
SE & 0.839 & 0.854 & & & \\
SEO & 0.719 & 0.749 & 0.789 & 0.596 & 0.095 & 0.625 \\
SI & 0.636 & 0.642 & 0.633 & 0.099 & 0.091 \\
UB & 0.086 & 0.501 & 0.231 & 0.720 & 0.715 & \\
\hline
\end{tabular}

The results of construct research, as well as the related convergent validity and discriminant validity tests, verified the accuracy and suitability of the measurement scale used in this study (Tables 1 and 2).

\subsection{Structural model}

The structural model was tested using a variety of tests, including R2, beta, $\mathrm{t}$-values via bootstrapping alongside a 1,000 resample, predictive relevance (Q2), and VIF, as recommended by Hair et al. (2016). The second-order construct was evaluated in terms of interactions related to online reviews and digital coupon sales promotion, as seen in Fig. 2.



Fig. 2. Structural Model

Table 3

Testing direct relationships

\begin{tabular}{cccccccccc}
\hline & Path & St, $\beta$ & St. d & $\mathrm{R}^{2}$ & $\mathrm{Q}^{2}$ & $\mathrm{~F}^{2}$ & VIF & T-value & P-value \\
\hline H1 & IOT $\rightarrow$ SEO & 0.693 & 0.163 & 0.483 & 0.312 & 0.418 & 1.327 & 4.251 & 0.000 \\
H2 & IOT $\rightarrow$ UB & 0.548 & 0.136 & 0.300 & & 0.565 & 1.452 & 4.029 & 0.000 \\
H3 & UB $\rightarrow$ SEO & 0.211 & 0.070 & & 0.458 & 1.126 & 3.014 \\
\hline
\end{tabular}

Table 4

Testing mediating effect

\begin{tabular}{cccccccc}
\hline & Path & St, $\beta$ & St. d & T-value & LL (2.5\%) & UL (97.5\%) & P-value \\
\hline H4 & IOT $\rightarrow$ UB $\rightarrow$ SEO & 0.127 & 0.043 & 2.959 & 0.044 & 0.208 & 0.003 \\
\hline
\end{tabular}

In terms of direct relationships, the structural model (Table 3) states the following: The impact of IOT on SEO was the focus of $\mathrm{H} 1$, while the impact of IOT on User Behavior was the focus of $\mathrm{H} 2$. H3 was also about the effect of User Behavior on SEO. The mediating function of User Behavior between IoT and SEO was mentioned in the structural model for H4 as shown in (Table-4). The following are the findings from the H1 review of the effect of IOT on SEO: The T-value was 4.251, the St, B was 0.693 , and the p-value was 0.000 . (one-tailed). The following are the findings from the study of $\mathrm{H} 2$ : the effect of IoT on User Behavior: p-value of 0.000, T-value of 4.029, St, B of 0.548, and T-value of 4.029 (one-tailed). The following are the findings from the $\mathrm{H} 3$ review of the effect of User Behavior on SEO: The analysis related to $\mathrm{H} 4$ regarding the mediating effect of User Behavior on the relationship between IOT and SEO yielded the following results: T-value of 3.014, St, B of 0.211, and p-value of 0.001 (one-tailed); also, the analysis related to $\mathrm{H} 4$ regarding the mediating effect of User Behavior on the relationship between IoT and SEO yielded the following results: The T-value was 2.959 , the St, B was 0.127 , and the p-value was 0.003 . (two-tailed). The findings accounted for approximately $48.3 \%$ of the variance in SEO since the R2 value associated 
with User Behavior was determined to be 0.483 , and approximately 30.0 percent of the variance in User Behavior since the R2 value associated with User Behavior was determined to be 0.300 (Table 3), which is consistent with Chin's (1998) suggested threshold value of 0.19 . In terms of F2 values, the IoT with SEO predictor had a value of 0.418, the IoT with User Behavior predictor had a value of 0.565 , and the User Behavior with SEO predictor had a value of 0.458. The degree to which each of the predictors described the User Behavior and SEO was expressed in these values. Furthermore, the Q2 value associated with SEO was greater than 0 (0.312), indicating that the model is suitable for prediction (Chin, 2010). Furthermore, the model's overall goodness of fit and predictive relevance is satisfactory, with the VIF value associated with each inner model not exceeding 5 (1.126 - 1.452) on average (Hair et al., 2017). The results obtained, as shown in Table 3, verified the validity of the model with respect to the direct relationship $(\mathrm{H} 1, \mathrm{H} 2$ and $\mathrm{H} 3)$ as well as the mediating effects of User Behavior between IOT and SEO (H4) in Table 4.

\section{Findings discussion}

In terms of the IoT' effect, the current study's findings showed that it had a positive direct significant impact on SEO, indicating that $\mathrm{H} 1$ was supported. This result is consistent with previous research that has found that the IoT plays a key role in enhancing SEO (Fahlström \& Jensen, 2016; Ozbek et al., 2015; Okiko, 2012). As a result, begin and continue to use technology, as well as improve the efficiency of technology applications and resources that provide users with knowledge relevant to their searches. In terms of the relationship between the IoT and User Behavior, the findings revealed that the IoT had a positive direct significant impact on User Behavior, implying that $\mathrm{H} 2$ was supported. This result is consistent with Cata \& Martz (2015) and Zolkepli et al. (2020) who found a positive relationship between the IoT and User Behavior. Controlling IoT networks and setting default modes for smart products can help companies influence these trends. The effect was positive, direct, and significant in the relationship between User Behavior and SEO, so H3 was supported. The possible implications may be that human behavior and mentality lead to improving the search engine by searching for the best options through improved device programming algorithms that enable search results to provide users with information. In terms of the role of user behavior in mediating the relationship between IoT construct and SEO, the current study found that user behavior mediated the relationship between IoT construct and SEO, indicating that H4 was supported. This means that human thoughts and attitudes motivate and enhance the device programming algorithms through.

\section{Conclusion}

This study aimed to fill a gap in the literature by looking into the relationship between the IoT and SEO among employees of Jordanian telecommunication companies, as well as the relationship between the IoT and User Behavior. It also looked into the relationship between user behavior and SEO. It also looked into the importance of user behavior as a mediating factor in the relationship between the IoT and SEO. Based on the findings and discussion presented here, it appears that this study has made a significant contribution by increasing understanding of the impact of the IoT on user behavior and SEO, as well as the mediating role of user behavior on that relationship in the context of Jordanian telecommunication companies, which has yet to recognize this relationship. To test the research hypotheses about the effect of the IoT on user behavior and SEO, the researchers used PLS-SEM 3.2.8. According to the results, the IoT had a positive and significant effect on SEO, as well as a positive and significant impact on user behavior. Similarly, user behavior influenced SEO in a constructive and important way. The study also discovered that in Jordanian telecommunication companies, user behavior played a mediating role in the relationship between the IoT and SEO. Thus, in a highly competitive market, user behavior clearly plays a critical role in enhancing SEO through the use of the IoT.

\section{Future work and recommendations}

A variety of guidelines for future research are suggested in the present study. To begin with, as the current research was conducted in Jordan, a similar study should be conducted in other countries to allow for comparison of outcomes. Other variables, such as customer experience in the same relationship, should be included as well, given that this study looked at the mediating role of user behavior in the process of company decision-making. Another noteworthy feature of this research is the use of a two-stage approach in evaluating reflective structures and measures, which can be applied to other studies of a similar nature.

\section{References}

Agichtein, E., Brill, E., \& Dumais, S. (2006, August). Improving web search ranking by incorporating user behavior information. In Proceedings of the 29th annual international ACM SIGIR conference on Research and development in information retrieval (pp. 19-26).

Ahmad, A., Madi, Y., Abuhashesh, M., M Nusairat, N., \& Masa'deh, R. E. (2020). The Knowledge, Attitude, and Practice of the Adoption of Green Fashion Innovation. Journal of Open Innovation: Technology, Market, and Complexity, 6(4), 107.

Aldossari, M. Q., \& Sidorova, A. (2020). Consumer acceptance of Internet of Things (IoT): Smart home context. Journal of Computer Information Systems, 60(6), 507-517. 
Al-Gasawneh, J., \& Al-Adamat, A. (2020). The mediating role of e-word of mouth on the relationship between content marketing and green purchase intention. Management Science Letters, 10(8), 1701-1708.

Alghasawneh, L. A. S., Akhorshaideh, A. H., Alharafsheh, M., Ghasawneh, A., Al-Gasawneh, J. A., \& Al-Hadid, A. Y. (2021). Determinants of Supply Chain Management Practices in Jordanian Pharmaceutical Firms. Solid State Technology, 64(2), 2986-3001.

Al-Saedi, K., Al-Emran, M., Ramayah, T., \& Abusham, E. (2020). Developing a general extended UTAUT model for Mpayment adoption. Technology in Society, 62, 101293.

Arfi, W. B., Nasr, I. B., Khvatova, T., \& Zaied, Y. B. (2021). Understanding acceptance of eHealthcare by IoT natives and IoT immigrants: An integrated model of UTAUT, perceived risk, and financial cost. Technological Forecasting and Social Change, 163, 120437

Atzori, L., Iera, A., \& Morabito, G. (2010). The internet of things: A survey. Computer Networks, 54(15), $2787-2805$.

Baron, R. M., \& Kenny, D. A. (1986). The moderator-mediator variable distinction in social psychological research: Conceptual, strategic, and statistical considerations. Journal of Personality and Social Psychology, 51(6), 1173.

Berman, R., \& Katona, Z. (2013). The role of search engine optimization in search marketing. Marketing Science, 32(4), 644651.

Can, U., \& Alatas, B. (2017). Big social network data and sustainable economic development. Sustainability, 9(11), 2027.

Cata, T., \& Martz, B. (2015). Comparing mobile APPs usability characteristics for designers and users. Journal of International Technology and Information Management, 24(4), 4.

Chin, J., Callaghan, V., \& Allouch, S. B. (2019). The Internet-of-Things: Reflections on the past, present and future from a user-centered and smart environment perspective. Journal of Ambient Intelligence and Smart Environments, 11(1), 45-69.

Chin, W. W. (1998). Commentary: Issues and opinion on structural equation modeling.

Chin, W. W. (2010). How to write up and report PLS analyses. In Handbook of partial least squares (pp. 655-690). Springer, Berlin, Heidelberg

Drivas, I. C., Sakas, D. P., Giannakopoulos, G. A., \& Kyriaki-Manessi, D. (2020). Big data analytics for search engine optimization. Big Data and Cognitive Computing, 4(2), 5.

Dwivedi, Y. K., Rana, N. P., Jeyaraj, A., Clement, M., \& Williams, M. D. (2019). Re-examining the unified theory of acceptance and use of technology (UTAUT): Towards a revised theoretical model. Information Systems Frontiers, 21(3), 719-734.

Efendioglu, A., \& Igna, F. (2011). Attracting customers online: effectiveness of online marketing tools. Master's dissertation, Lulea University of Technology, Luleå, Sweden.

El-Masri, M., \& Tarhini, A. (2017). Factors affecting the adoption of e-learning systems in Qatar and USA: Extending the Unified Theory of Acceptance and Use of Technology 2 (UTAUT2). Educational Technology Research and Development, 65(3), 743-763.

Fahlström, K., \& Jensen, C. (2016). Search Engine Marketing in SMEs: The motivations behind using search engine marketing.

Folorunso, O., Ogunseye, O. S., \& Sharma, S. K. (2006). An exploratory study of the critical factors affecting the acceptability of e-learning in Nigerian universities. Information management \& computer security.

Fremantle, P., \& Scott, P. (2017). A survey of secure middleware for the Internet of Things. Peer Journal of Computer Science, 3, e114.

Gao, T., \& Deng, Y. (2012, June). A study on users' acceptance behavior to mobile e-books application based on UTAUT model. In 2012 IEEE International Conference on Computer Science and Automation Engineering (pp. 376-379). IEEE.

Gefen, D., Rigdon, E. E., \& Straub, D. (2011). Editor's comments: An update and extension to SEM guidelines for administrative and social science research. Management Information Systems Quarterly, 35(2), 3-16.

George, D. (2005). The ABC of Seo. Lulu. com.

Goldman, E. (2005). Search engine bias and the demise of search engine utopianism. Yale JL \& Tech., 8, 188.

Green, S. B. (1991). How many subjects does it take to do a regression analysis? Multivariate Behavioral Research, 26(3), 499-510.

Grubor, A., \& Jakša, O. (2018). Internet marketing as a business necessity. Interdisciplinary Description of Complex Systems: INDECS, 16(2), 265-274.

Hair Jr, J. F., Hult, G. T. M., Ringle, C., \& Sarstedt, M. (2016). A primer on partial least squares structural equation modeling (PLS-SEM). Sage publications.

Hair Jr, J. F., Sarstedt, M., Ringle, C. M., \& Gudergan, S. P. (2017). Advanced issues in partial least squares structural equation modeling. saGe publications.

Hair, J. F., Black, W. C., Babin, J., \& Anderson, R. E. (2010). Multivariate data analysis (7th ed.). Upper Saddle River.

Hammouri, Q. M., Abu-Shanab, E. A., \& Nusairat, N. M. (2021a). Attitudes Toward Implementing E-Government in Health Insurance Administration. International Journal of Electronic Government Research (IJEGR), 17(2), 1-18.

Hammouri, Q., \& Altaher, A. (2020). The Impact of Knowledge Sharing on Employees Satisfaction. International Journal of Psychosocial Rehabilitation, 24(10).

Hammouri, Q., \& Abu-Shanab, E. A. (2020). Major Factors Influencing the Adoption of Cloud Computing in Jordan. International Journal of Technology and Human Interaction (IJTHI), 16(4), 55-69. 
Hammouri, Q., Al-Gasawneh, J. A., Nusairat, N. M., Hanandeh, A., \& Barakat, S. (2021b). The Determinants of Trust and its Influence on Online Buying Intention: An Empirical Study on Social Commerce in Jordan. Annals of the Romanian Society for Cell Biology, 4522-4539.

Hatab, R. (2014). Improve website rank using search engine optimization (SEO) (Doctoral dissertation, MS thesis. https://www.researchgate.net/publication/275637141_Improve_Website_Rank_Using_Search_Engine_OptimizationSEO. Last accessed 2019/01/10).

Hawamleh, A. M. A., Alorfi, A. S. M., Al-Gasawneh, J. A., \& Al-Rawashdeh, G. (2020). Cyber Security and Ethical Hacking: The Importance of Protecting User Data. Solid State Technology, 63(5), 7894-7899.

Henseler, J., Ringle, C. M., \& Sarstedt, M. (2015). A new criterion for assessing discriminant validity in variance-based structural equation modeling. Journal of the Academy of Marketing Science, 43(1), 115-135.

Herrero, Á., \& San Martín, H. (2017). Explaining the adoption of social networks sites for sharing user-generated content: A revision of the UTAUT2. Computers in Human Behavior, 71, 209-217.

Hsiao, M. H. (2018). A conceptual framework for technology-enabled and technology-dependent user behavior toward device mesh and mesh app. Future Business Journal, 4(1), 130-138.

Huang, J., Zhang, X., Tan, L., Wang, P., \& Liang, B. (2014, May). Asdroid: Detecting stealthy behaviors in android applications by user interface and program behavior contradiction. In Proceedings of the 36th International Conference on Software Engineering (pp. 1036-1046).

Ištvanić, M., Crnjac Milić, D., \& Krpić, Z. (2017). Digital Marketing in the business environment. International Journal of Electrical and Computer Engineering Systems, 8(2), 67-75.

Jaradat, M. I. R. M., Ababneh, H. T., Faqih, K. M., \& Nusairat, N. M. (2020). Exploring Cloud Computing Adoption in Higher Educational Environment: An Extension of the UTAUT Model with Trust.

Johansson, A. (2016). Clustering User-Behavior in a Collaborative Online Social Network: A Case Study on Quantitative User-Behavior Classification.

Khalilzadeh, J., Ozturk, A. B., \& Bilgihan, A. (2017). Security-related factors in extended UTAUT model for NFC based mobile payment in the restaurant industry. Computers in Human Behavior, 70, 460-474.

Khanna, A., \& Kaur, S. (2019). Evolution of Internet of Things (IoT) and its significant impact in the field of Precision Agriculture. Computers and Electronics in Agriculture, 157, 218-231.

Kramp, T., Van Kranenburg, R., \& Lange, S. (2013). Introduction to the Internet of Things. In Enabling Things to Talk (pp. 1-10). Springer, Berlin, Heidelberg.

Kritzinger, W. T., \& Weideman, M. (2013). Search engine optimization and pay-per-click marketing strategies. Journal of Organizational Computing and Electronic Commerce, 23(3), 273-286.

Kumar, N. M., \& Mallick, P. K. (2018). Blockchain technology for security issues and challenges in IoT. Procedia Computer Science, 132, 1815-1823.

Lemos, J. Y., \& Joshi, A. R. (2017, February). Search engine optimization to enhance user interaction. In 2017 International Conference on I-SMAC (IoT in Social, Mobile, Analytics and Cloud) (I-SMAC) (pp. 398-402). IEEE.

Machogu, A.M. \& Okiko, L. (2012). The perception of bank employees towards cost of adoption, risk of innovation, and staff Training's influence on the adoption of information and communication technology in the Rwandan commercial banks. Journal of Internet Banking and Commerce, 17, 1-15.

Masha'al Al Nahar, D. (2019). The Impact of Internet of Things (IoT) on Financial Services Quality: Field Study in Jordanian Commercial Banks. (Doctoral dissertation, Middle East University).

Mavridis, T., \& Symeonidis, A. L. (2015). Identifying valid search engine ranking factors in a Web 2.0 and Web 3.0 context for building efficient SEO mechanisms. Engineering Applications of Artificial Intelligence, 41, 75-91.

Mei-Ying, W., Pei-Yuan, Y., \& Weng, Y. C. (2012). A study on user behavior for i pass by UTAUT: Using taiwan's MRT as an example. Asia Pacific Management Review, 17(1).

Merhi, M., Hone, K., \& Tarhini, A. (2019). A cross-cultural study of the intention to use mobile banking between Lebanese and British consumers: Extending UTAUT2 with security, privacy and trust. Technology in Society, 59, 101151.

Muresan, G. (2009). An integrated approach to interaction design and log analysis. In Handbook of research on web log analysis (pp. 227-255). IGI Global.

Nasereddin, H. H., \& FAQIR, M. (2019). The impact of internet of things on customer service: A preliminary study. Periodicals of Engineering and Natural Sciences, 7(1), 148-155.

Nusairat, N., Hammouri, Q., Al-Ghadir, H., Ahmad, A., \& Eid, M. (2020). The effect of design of restaurant on customer behavioral intentions. Management Science Letters, 10(9), 1929-1938.

Ngah, A. H., Gabarre, S., Han, H., Rahi, S., Al-Gasawneh, J. A., \& Park, S. H. (2021). Intention to Purchase Halal Cosmetics: Do Males and Females Differ? A Multigroup Analysis. Cosmetics, 8(1), 19.

Nguyen, B., \& Simkin, L. (2017). The Internet of Things (IoT) and marketing: the state of play, future trends and the implications for marketing. Journal of Marketing Management, 33(1-2).

Nwokoye, E. \& Ilechukwu, N. (2018). CHAPTER FIVE THEORY OF COSTS.

Ozbal, O., Duman, T., Topaloglu, O., 2019. Modeling peer-to-peer digital brand equity from service provider and user perspectives. Marketing Management Association, pp.12-20.

Ozbek, Volkan \& Günalan, Mustafa \& Koc, Fatih \& Şahin, Nisa \& Kaş, Eda. (2015). The Effects of Perceived Risk and Cost on Technology Acceptance: A Study on Tourists' Use of Online Booking. Celal Bayar Üniversitesi Sosyal Bilimler Dergisi. 13. 227-244. 10.18026/cbusos.49782. 
Palos-Sanchez, P., Saura, J. R., Reyes-Menendez, A., \& Esquivel, I. V. (2018). Users acceptance of location-based marketing apps in tourism sector: an exploratory analysis. Journal of Spatial and Organizational Dynamics, 6(3), 258-270.

Rahi, S., \& Ghani, M. A. (2018). The role of UTAUT, DOI, perceived technology security and game elements in internet banking adoption. World Journal of Science, Technology and Sustainable Development, 15(4).

Ranaiey, S., Taghavi, M. R., \& Goodarzi, M. A. (2016). Development of a Measure: Internet Behaviors Scale. Modern Applied Science, $10(7)$.

Rashid, J., Adnan, S. M., Nisar, M. W., Irtaza, A., Arafat, S. Y., \& Iqbal, M. J. (2018, March). Advertiser's perception of Internet marketing for small and medium enterprises in Pakistan. In 2018 International Conference on Computing, Mathematics and Engineering Technologies (iCoMET) (pp. 1-7). IEEE.

Rio, R., \& Banker, S. (2014). IoT changes logistics for the OEM spare parts supply chain. ARC Insights, 1-5.

Sheikh, Z., Islam, T., Rana, S., Hameed, Z., \& Saeed, U. (2017). Acceptance of social commerce framework in Saudi Arabia. Telematics and Informatics, 34(8), 1693-1708.

Slade, E. L., Dwivedi, Y. K., Piercy, N. C., \& Williams, M. D. (2015). Modeling consumers' adoption intentions of remote mobile payments in the United Kingdom: extending UTAUT with innovativeness, risk, and trust. Psychology \& Marketing, 32(8), 860-873.

Venkatesh, V., \& Zhang, X. (2010). Unified Theory of Acceptance and Use of Technology: U.S. Vs. China. Journal of Global Information Technology Management, 13(1), 5-27. doi:10.1080/1097198x.2010.10856507

Venkatesh, V., Morris, M. G., Davis, G. B., \& Davis, F. D. (2003). User acceptance of information technology: Toward a unified view. MIS quarterly, 27(3), 425-478.

Venkatesh, V., Thong, J. Y., \& Xu, X. (2012). Consumer acceptance and use of information technology: extending the unified theory of acceptance and use of technology. MIS Quarterly, 36(1), 157-178.

Venkatesh, V., Thong, J. Y., \& Xu, X. (2016). Unified theory of acceptance and use of technology: A synthesis and the road ahead. Journal of the association for Information Systems, 17(5), 328-376.

Williams, M. D., Rana, N. P., \& Dwivedi, Y. K. (2015). The unified theory of acceptance and use of technology (UTAUT): a literature review. Journal of Enterprise Information Management, 28(3).

Witkowski, K. (2017). Internet of things, big data, industry 4.0-innovative solutions in logistics and supply chains management. Procedia Engineering, 182, 763-769.

Wu, J., Chen, J., \& Dou, W. (2017). The Internet of Things and interaction style: the effect of smart interaction on brand attachment. Journal of Marketing Management, 33(1-2), 61-75.

Yerpude, S., \& Singhal, T. K. (2017). Internet of Things and its impact on Business Analytics. Indian Journal of Science and Technology, 10(5), 1-6.

$\mathrm{Yu}, \mathrm{C}$. S. (2012). Factors affecting individuals to adopt mobile banking: Empirical evidence from the UTAUT model. Journal of Electronic Commerce Research, 13(2), 104.

Zainab, B., Awais Bhatti, M., \& Alshagawi, M. (2017). Factors affecting e-training adoption: an examination of perceived cost, computer self-efficacy and the technology acceptance model. Behaviour \& Information Technology, 36(12), 12611273.

Zaky, G., Shawky, A., \& Ragheb, M. A. (2020). Investigating the factors affecting the internet of things (IOT) adoption model-an exploratory study in Egypt. The Business \& Management Review, 11(2), 97-108.

Zeinab, K. A. M., \& Elmustafa, S. A. A. (2017). Internet of things applications, challenges and related future technologies. World Scientific News, 2(67), 126-148.

Ziakis, C., Vlachopoulou, M., Kyrkoudis, T., \& Karagkiozidou, M. (2019). Important factors for improving Google search rank. Future Internet, 11(2), 32.

Zolkepli, I. A., Mukhiar, S. N. S., \& Tan, C. (2020). Mobile consumer behaviour on apps usage: The effects of perceived values, rating, and cost. Journal of Marketing Communications, 1-23.

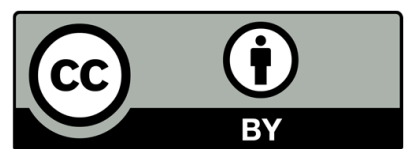

(C) 2021 by the authors; licensee Growing Science, Canada. This is an open access article distributed under the terms and conditions of the Creative Commons Attribution (CC-BY) license (http://creativecommons.org/licenses/by/4.0/). 